E3S Web of Conferences 1, 37003 (2013)

DOI: $10.1051 / \mathrm{e} 3$ sconf/20130137003

(C) Owned by the authors, published by EDP Sciences, 2013

\title{
A novel solidified floating organic drop microextraction method for preconcentration and determination of copper ions by flow injection flame atomic absorption spectrometry in water samples
}

\author{
Ç. Arpa Șahin, I. Durukan and S. Bektaş
}

Hacettepe University, Chemistry Department, 06800, Beytepe, Ankara, TURKEY; carpa@hacettepe.edu.tr

\begin{abstract}
A simple, rapid and inexpensive solidified floating organic drop microextraction (SFODME) and flow injection flame atomic absorption spectrometric determination (FI-FAAS) method for copper was developed. 3-amino-7-dimethylamino-2-methylphenazine (Neutral red, NR) was used as the complexing agent. Several factors affecting the microextraction efficiency, such as, $\mathrm{pH}$, NR and sodium dodecylbenzenesulfonate (SDBS) concentration, extraction time, stirring rate, and temperature were investigated and optimized. Under optimized experimental conditions an enrichment factor of 541 was obtained for $100 \mathrm{~mL}$ of sample solution. The calibration graph was linear in the range of $0.5-20.0 \mathrm{ng} \mathrm{mL}^{-1}$ and the limit of detection $(3 s)$ was $0.18 \mathrm{ng} \mathrm{mL}^{-1}$, the limit of quantification $(10 s)$ was $0.58 \mathrm{ng} \mathrm{mL}$. The relative standard deviation (RSD) for 10 replicate measurements of $10 \mathrm{ng} \mathrm{mL}^{-1}$ copper was $2.7 \%$. The developed method was successfully applied to the extraction and determination of copper in different certified reference materials (Estuarine water, Slew 3 and fortified water, TM 23.2) and real water samples and satisfactory results were obtained.
\end{abstract}

Key words: Copper determination; solidified floating organic drop microextraction; preconcentration; flow injection; flame atomic absorption spectrometry; Neutral Red; SDBS

\section{Introduction}

Copper is an economically important element that is found in only trace quantities in the Earth's crust. For both plants and animals it is required as a trace nutrient, but excessive amounts are toxic [1]. High amounts of copper in the human body can cause stomach and intestinal distress such as nausea, vomiting, diarrhea and stomach cramps. It is well known that the free cupric ion is highly toxic for marine organisms and its determination is an important analytical task $[2,3]$. Therefore, it is necessary from an analytical point of view to develop sensitive and economical methods for the determination of trace amount of copper. Recent advances in analytical instrumentation enable the analysis of many samples at high speed [4,5]. However, despite these advances it is still often necessary to use separation and preconcentration methods prior to the quantitative determination, mainly because of the low-level concentration common in toxic species determinations. Better detection limit values might be obtained by a complete separation of the species of interest. Thus, for determination of samples of low analyte content, it is necessary to incorporate a preconcentration step in the analytical procedure. Liquid-liquid extraction (LLE) is among the oldest of the preconcentration and matrix isolation techniques in analytical chemistry. However, some disadvantages such as the emulsion formation, the use of large sample volumes and toxic organic solvents and the generation of large amounts of pollutants makes LLE expensive, time-consuming and environmentally unfriendly. For this reason, miniaturization of the liquid-liquid extraction attempts to eliminate or minimize these drawbacks. In this sense, SFODME technique was started to be used an alternative to other microextraction techniques in 2007.

In SFODME technique, a free microdrop of the organic solvent which has a melting point near room temperature in the range of $10-30{ }^{\circ} \mathrm{C}$ is transferred to the surface of an aqueous sample, while being agitated by a stirring bar in the bulk of the solution. Under the proper stirring conditions, the suspended microdrop can remain in the top-center position of the aqueous sample. After the completion of the extraction, the sample vial is cooled and the solidified microdrop is transferred into a conical vial, where it melts immediately. Finally, the analytes can 
be determined in the extractant.

In the present work a simple, selective, sensitive and cost effective SFODME method for preconcentration and FI-FAAS determination of copper ions in various water samples using NR as complexing agent and 1-dodecanol as extraction solvent was established.

\section{Materials and Methods}

For SFODME, aliquots of $100 \mathrm{~mL}$ containing sample or standard solution of copper was prepared and placed in $100 \mathrm{~mL}$ beaker containing a stirrer bar. After $\mathrm{pH}$ adjustment with $2 \mathrm{~mL}$ of $\mathrm{pH}: \sim 6.0$ acetate buffer, $500 \mu \mathrm{L}$ of $0.1 \%(\mathrm{~m} / \mathrm{v})$ of chelating agent NR and $100 \mu \mathrm{L}$ of $0.05 \%(\mathrm{w} / \mathrm{v})$ SDBS in 1-dodecanol were added. Then, magnetic stirrer was turned on and the solution was stirred for $20 \mathrm{~min}$ at $300 \mathrm{rpm}$. Under the proper stirring conditions, the organic solvent droplet floating on the surface of the aqueous solution due to its lower density than water was obtained. During the stirring step $\mathrm{Cu}(\mathrm{II})$ ions reacted with $\mathrm{NR}$ and were extracted into 1-dodecanol. After extraction time was over, the beaker was placed in the refrigerator $\left(4{ }^{\circ} \mathrm{C}\right)$ in order to solidify the organic solvent. Because of melting point close to room temperature $\left(24{ }^{\circ} \mathrm{C}\right)$ of 1-dodecanol the solidified drop was obtained in $10 \mathrm{~min}$. Then the solidified solvent was immediately transferred to a conical vial by a mini spatula and was diluted to $300 \mu \mathrm{L}$ with methanol. After this step, $200 \mu \mathrm{L}$ sample loop of FI 400 system was filled with the diluted organic phase in fill position of valve. Then the valve was switched to the inject position and the solution was directly introduced into the FAAS nebulizer in the presence of methanol as carrier solution.

\section{Results and Discussion}

Several factors affecting the microextraction efficiency, such as, type of extraction solvent, $\mathrm{pH}, \mathrm{NR}$ and sodium dodecylbenzenesulfonate (SDBS) concentration, extraction time, stirring rate, temperature and existence of other ions were investigated and optimized. A summary of optimum condition values obtained for SFODME for preconcentration and determination of copper is presented in Table 1.

\section{Validation studies}

In the optimum conditions of SFODME procedure the calibration graphs were linear in the range of 0.5-20.0 ng $\mathrm{mL}^{-1}$ copper. The regression equation for copper determination was $\mathrm{A}=2.12 \times 10^{-2} \mathrm{C}+1.42 \times 10^{-2}$, where $\mathrm{A}$ is the absorbance and $\mathrm{C}$ is the metal ion concentration in solution $\left(\mathrm{ng} \mathrm{mL} L^{-1}\right)$. The correlation coefficient of the calibration curve equation was higher than 0.99 . The equation obtained by direct aspiration in FAAS without the preconcentration procedure was $\mathrm{A}=3.92 \times 10^{-5} \mathrm{C}+$ $1.36 \times 10^{-2}\left(R^{2}=0.99\right)$; linear range between $250-10000$ $\mathrm{ng} \mathrm{mL}^{-1}$. The enhancement factor calculated as the ratio of the slope of calibration curve of the analytes after
Table 1. Optimum conditions for SFODME of copper ions.

\begin{tabular}{ll}
\hline $\begin{array}{l}\text { Optimum conditions for } \\
\text { SFODME of } \mathbf{C u}\end{array}$ & Value \\
\hline Extraction solvent & 1-dodecanol \\
ethanol \\
Diluent/carrier & $\sim 6$ \\
$\mathrm{pH}$ & 0.1 \\
$\mathrm{NR}$ concentration $(\%, \mathrm{w} / \mathrm{v})$ & 0.05 \\
SDBS concentration $(\%, \mathrm{w} / \mathrm{v})$ & 20 \\
Extraction time $(\mathrm{min})$ & 300 \\
Stirring rate $(\mathrm{rpm})$ & 100 \\
Sample volume, $\mathrm{mL}$ & 0.300 \\
Extracted phase volume, $\mathrm{mL}$ & Room temperature \\
Extraction temperature $\left({ }^{\circ} \mathrm{C}\right)$ & \\
\hline
\end{tabular}

preconcentration to that of prior preconcentration was found as 541 .

The precision of the method was calculated as the relative standard deviation of 10 independent measurements carried out using $10 \mathrm{ng} \mathrm{mL}^{-1}$ copper and found as $2.7 \%$. The limit of detection (LOD), defined as the concentration equivalent to three times the standard deviation (3s) of 10 measurements of the blank was found as $0.18 \mathrm{ng} \mathrm{mL}^{-1}$. The limit of quantification (LOQ) is the lowest level of analyte that can be accurately and precisely measured. LOQ, defined as ten times the standard deviation $(10 s)$ of 10 measurements was found as $0.58 \mathrm{ng} \mathrm{mL}^{-1}$.

To demonstrate the performance of the proposed method, recovery experiments were carried out by certified reference materials. TM To demonstrate the performance of the proposed method, recovery experiments were carried out by certified reference materials. TM 23.2 (fortified water) and Slew 3 (estuarine water) were used for method validation. Results are the average of three replicates. There is a good agreement between the obtained results and the known values. The recoveries indicate that the proposed system was successful for the determination of copper. A summary of optimum condition values obtained for SFODME for preconcentration and determination of copper is presented in Table 2.

Table 2. Analytical characteristics of the method

\begin{tabular}{ll}
\hline Parameter & $\begin{array}{l}\text { Analytical } \\
\text { Feature }\end{array}$ \\
\hline Preconcentration factor & 333 \\
$\begin{array}{l}\text { Enrichment factor } \\
\text { Limit of detection, }\end{array}$ & 541 \\
$\mathrm{ng} \mathrm{mL}^{-1}(3 s)$ & 0.18 \\
$\begin{array}{l}\text { Limit of quantification, } \\
\mathrm{ng} \mathrm{mL}(10 s)\end{array}$ & 0.58 \\
$\begin{array}{l}\text { Precision }\left(10 \mathrm{ng} \mathrm{mL}^{-1}, n=10\right) \mathrm{RSD} \\
(\%)\end{array}$ & 2.7 \\
Linear range, $\mathrm{ng} \mathrm{mL}^{-1}$ & $0.5-20.0$ \\
\hline
\end{tabular}


Table 3. Determination of copper in tap and sea water samples $(n=3)$

\begin{tabular}{lllll}
\hline Sample & $\begin{array}{l}\text { Added } \\
\left(\mu \mathbf{g ~ L}^{-1}\right)\end{array}$ & $\begin{array}{l}\text { Estimated } \\
\left(\mu \mathbf{~ L}^{-1}\right)\end{array}$ & $\begin{array}{l}\text { Found } \\
\left(\mu \mathbf{g ~ L}^{-1}\right)\end{array}$ & Recovery \% \\
\hline Tap water & 0 & - & $1.8 \pm 0.4$ & - \\
& 5.0 & 6.8 & $6.6 \pm 0.3$ & 97.1 \\
& 10.0 & 11.8 & $11.6 \pm 0.9$ & 98.3 \\
Sea water & 0 & - & $3.6 \pm 0.2$ & - \\
(Marmara Sea) & 5.0 & 8.6 & $8.4 \pm 0.5$ & 97.7 \\
& 10.0 & 13.6 & $13.1 \pm 0.3$ & 96.3 \\
\hline
\end{tabular}

Analyses of real samples

The recovery experiments were carried out by spiking different water samples in order to validate the method. For this purpose, different amounts of copper were added to $100 \mathrm{~mL}$ of tap water (Ankara, Turkey) and $100 \mathrm{~mL}$ sea water (Marmara Sea, Turkey). The results are shown in Table 3. The recovery values calculated for the added amounts were always higher than $97 \%$, and these results confirm the validity of the method.

\section{Conclusion}

SFODME combined with FI-AAS provides a simple way for the determination of copper in natural waters. Simplicity, low cost, good accuracy and precision, simple apparatus and minimum organic solvent consumption are the main advantages of proposed technique. Moreover, a high preconcentration factor was obtained easily by this method. In comparison with the other microextraction procedures extraction time can be relatively long but, with the help of a multi-stirrer fifteen samples can be extracted at the same time. Additional studies are in progress on evaluating the performance of SFODME method for preconcentration and determination of different metals by using various complexing agents.

\section{References}

[1] G.W. vanLoon, S.J. Duffy, Environmental Chemistry, A Global Perspective, Oxford University Press Inc., New York, 2000, pp: 271-273.

[2] S.Z. Mohammadi, D. Afzali, Y.M. Baghelani, Ligandless-dispersive liquid-liquid micro extraction of trace amount of copper ions, Anal. Chim. Acta 2009; 653:173-177.

[3] M. Soylak, O. Ercan, Selective separation and preconcentration of copper (II) in environmental samples by the solid phase extraction on multi-walled carbon nanotubes, J. Hazard. Mater. 2009; 168: 1527-1531.

[4] M.C.T. Diniz, O.F. Filho, J.J.R. Rohwedder, An automated system for liquid-liquid extraction based on a new micro-batch extraction chamber with on-line detection, preconcentration and determination of copper(II), Anal. Chim. Acta 2004; 525:281-287.

[5] A. Tobiasz, S. Walas, B. Trzewik, P. Grzybek, M. M. Zaitz, M. Gawin, H. Mrowiec, Cu(II)-imprinted styrene-divinylbenzene beads as a new sorbent for flow injection-flame atomic absorption determination of copper Microchem. J. 2009; 93:87-92.

[6] Z.B. Alfassi and C.M. Wai, Preconcentration Techniques for Trace Elements, CRC Press, Boca Raton, Florida 199).

[7] A. Stafiej, K. Pyrzynska, Solid phase extraction of metal ions using carbon nanotubes, Microchem. J. 2008; 89:29-33.

[8] Ç. Arpa Şahin, İ. Tokgöz, A novel solidified floating organic drop microextraction method for preconcentration and determination of copper ions by flow injection flame atomic absorption spectrometry, Anal. Chim. Acta 2010; 667:83-87.

[9] A.N. Anthemidis, M. Miro, Recent Developments in Flow Injection/Sequential Injection Liquid-Liquid Extraction for Atomic Spectrometric Determination of Metals and Metalloids, Appl Spectrosc Rev, 2009; 44: 140-167.

[10] F.P. Pereira, I. Lavilla and C. Bendicho, Miniaturized preconcentration methods based on liquid-liquid extraction and their application in inorganic ultratrace analysis and speciation: a review, Spectrochim. Acta B 2009; 641-15.

[11] US Environmental Protection Agency, SW-846, Test Methods for Evaluating Solid Waste: Physical/Chemical Methods, 3rd ed., US GPO, Washington, DC, USA, 1986. 